\title{
Patients' satisfaction with mental health nursing interventions in the management of anxiety: Results of a questionnaire study
}

\author{
S. Webster ${ }^{1}$, S. Gallaher ${ }^{1}$, V. Lopez ${ }^{2}$, Peter Brown ${ }^{3}$, J . Evans ${ }^{1}$ \\ 1. School of Nursing, Australian Catholic University, New South Wales, Australia. 2. Research centre for Nursing and \\ Midwifery, Australian National University, Australia. 3. Charles Darwin University, Northern Territory, Australia
}

Correspondence: S. Webster. Address: School of Nursing, Australian National University, New South Wales, Australia. Telephone: 61-297-392-387. Email: sue.webster@acu.edu.au

Received: November 14, 2011

Accepted: January 3, 2012

Published: May 1, 2012

DOI : $10.5430 /$ jnep.v2n2p52

URL: http://dx.doi.org/10.5430/jnep.v2n2p52

\section{Abstract}

Objective: Patients' satisfaction is a significant indicator of the quality of care provided in a health setting. The purpose of this study was to identify aspects of mental health nursing care that are most likely to influence satisfaction with patients who are experiencing anxiety in two private mental health care setting.

Method: Study design: A survey of a sample of patients in two private mental health hospitals in Sydney, Australia where patients were asked to evaluate their overall experience of this episode of care and to complete the Patients' Satisfaction Questionnaire on specific aspects of their care for anxiety. Two hundred (200) Questionnaires were left with the participants to be completed at discharge, and there were 189 (94\%) questionnaires returned.

Results: One hundred and eighty nine patients (189) completed the survey. Representing 94\% of respondents they indicated that they were satisfied with the mental health nurses intervention for their anxiety. There were no significant differences found between genders, age groups, marital status, number of admissions and duration of hospitalisations. A multiple linear regression indicated that the major determinants of patient satisfaction were emotional support and respect for patient preferences. The results of satisfaction scores demonstrated evidence of construct validity of total scale with total mean rating of all domain $3.70(\mathrm{SD}=0.67)$ and Reliability coefficients for the total scale were .93 , however, mean rating for the 5 domains was $3.69(\mathrm{SD}=0.66)$.

Conclusions: The finding of this preliminary patients' satisfaction study suggests that mental health nurses with appropriate education and supervision can provide an effective therapeutic approach to patients who are experiencing anxiety in these two private mental health settings.

\section{Key words}

Mental health nursing intervention, Patient experiencing anxiety, Private hospital setting, Patient satisfaction

\section{I ntroduction}

In Australia, there has been an increasing emphasis on the use of patients' satisfaction surveys in publicly funded health services to access elements of quality of care. These questionnaires focus on specific dimensions of patient care - including 
information and communication, coordination of care, respect of patient preferences, involvement of family and friends, and continuity and transition ${ }^{[1]}$. However, the questionnaires do not ask if patients are satisfied with these aspects of care but, instead, whether certain processes and events occurred during the course of a specific episode of care. Therefore, this study evaluated the satisfaction of patients with mental health nursing interventions for patients experiencing anxiety in the mental health setting has met with this specific aspect of evaluation.

Anxiety and depression are the two most common mental health problems seen in medical settings ${ }^{[2]}$. Anxiety manifests itself in every aspect of a person's being and produces cognitive (e.g. confusion, poor concentration, or inability to focus on immediate concerns), affective (e.g. apprehension, fearfulness, or dread) and physiological manifestation (e.g. shortness of breath, insomnia, cardiac palpitations, tension, and fatigue) ${ }^{[2]}$. Anxiety is a common subjective experience that signals a threat of some type and stimulates the stress response, which can be a debilitating condition with economic consequences such as time off work ${ }^{[3]}$. Anxiety and depression influence mood, life expectations and motivation of people and are the most prevalent mental health disorders ${ }^{[4]}$. However, anxiety may occur in the context of other mental states such as co-morbidity associated with substance use disorders ${ }^{[5]}$. Previous research on stress in health care has shown that patients react emotionally to being in a hospital environment. Those who cope well and use problem focused coping, (e.g. self-talk), have better psychological outcomes ${ }^{[5,6]}$. This research identifies nursing strategies and interventions that assist patients to cope with anxiety and de-stress adaptation elements.

The provision of care for individuals with mental health problems has changed dramatically over the past decade and the role of mental health nurses has undergone radical change ${ }^{[6]}$. These changes encompass areas such as supporting, promoting and educating clients and their carers ${ }^{[7,8]}$. Mental health nurses possess a range of skills that can positively influence patients' mental health leading to recovery ${ }^{[9]}$. These authors confirm that the nurse patient relationship is pertinent and a critical element of nursing's paradigm that is essential in delivering nursing care ${ }^{[10]}$. Traditionally, assessments of patients have ignored the personal reports of patients in preference to technical and physiological reports of outcome. More recently, healthcare systems have sought to achieve a balance in services that offer not only clinically effective and evidence based care, but which are also judged by patients as acceptable and beneficial ${ }^{[10]}$.

\subsection{Background of the study}

Evaluation of healthcare provision is essential in the ongoing assessment and consequent quality improvement of health services. Patient satisfaction is not a clearly defined concept and most typically, it appears to represent patients' attitudes to care or aspects of care. While numerous questionnaires have been developed which ask people to rate aspects of care, such an approach has limitation ${ }^{[10]}$. Attitudes to services do not tell us very much about the specific nature of those services. Surveys of patient satisfaction tend to elicit very positive ratings that are not sensitive to specific problems in the quality of care delivery. It has been argued that questionnaires should attempt to measure patients' experiences of their care, and then determine how such experiences are related to satisfaction ${ }^{[12]}$.

From the review of the literature, evaluating the effectiveness of therapies for patients with anxiety and nursing interventions for patients with anxiety is limited ${ }^{[13]}$. In most countries, guidelines for the treatment of anxiety disorders are available for specialised mental health care ${ }^{[14]}$ such as in general practice ${ }^{[14,15]}$. However, hospital policies and guidelines vary from one health care setting to the next, for example, Heideman et al's ${ }^{[16]}$ review found that interventions for anxiety did not always fall in line with the standards provided by such guidelines and the clinicians' skills in managing anxiety varied considerably. These two private hospitals in this study have protocol; however, there was no guideline for management of anxiety.

Although mental health nursing practice has incorporated many aspects of the medical model, nursing theories and models have been well received within psychiatric and mental health nursing practice ${ }^{[17]}$. Mental health nurses increasingly focused on building a therapeutic alliance between the nurse and patient when managing a patient's challenging 
behaviour ${ }^{[17,18]}$. Moreover, the nurse's relationship with patients is grounded in day-to-day therapeutic experiences rather than in any established theory or empirical research. Dearing ${ }^{[19]}$ has similarly highlighted the importance of the nurse-patient relationship as the central concept of mental health nursing. Patton ${ }^{[20]}$ confirmed that the impact of nursing's outcomes has been limited and the effects of nursing management are unclear. In the present study nurses' interventions in relation to patient's anxiety are evaluated.

It is important to understand the interpersonal process between nurses and patients in mental health care when patients experience anxiety. It can be disabling for patients' thoughts and behaviour and have a negative influence on the recovery process. Through the use of nursing models and theories for planning patient care ${ }^{[19]}$, nurses will be able to clearly describe their role in relation to patient interventions ${ }^{[18]}$. The Tidal Model ${ }^{[17]}$, which has emerged from a series of studies on the 'need for mental health nursing', identifies the centrality of interpersonal relationship within nursing practice. The principle of the model is integrated into the nursing processes for re-empowering the person who is disempowered by anxiety and distress in this setting ${ }^{[20,21]}$. The nurse's role using this model is to engage and guide the person in relation to managing their distress and to enable them to develop strategies to cope with their anxiety. There is limited understanding in the health care system of the management of patient' anxiety and little in the way of management guidelines in respond to this issue.

Patients' satisfaction with their care while in hospital is considered an integral part of quality care ${ }^{[10,12]}$. Satisfied patients are more likely to comply with treatment recommendations, while patients who have a low level of satisfaction with their care may be less informed and educated, and thus lack the confidence to manage their condition at home ${ }^{[9]}$. This may lead to more frequent readmissions ${ }^{[10]}$.

\subsection{Purpose of the study}

1) Is there a significant relationship between respondent's perceptions of nursing interventions and their perceptions of quality of care?

2) Explore the factors that lead to satisfaction with nurses' intervention, as a meaningful indicator of patients' satisfaction with these healthcare services.

\section{Subjects and method}

\subsection{Study design}

Survey of a sample of patients who underwent a period of inpatient care in two private mental health care settings were asked to evaluate their overall experience of nursing interventions for their anxiety.

\subsection{Participants and settings}

The study was conducted in two private mental health hospitals in Sydney, Australia with combine number of 220 inpatients beds. These hospitals cover suburban city and semi-rural areas and service a population of approximately 830,000 persons.

Data were collected during a four months of the study period. All inpatients were given the study information form for voluntary participation in this study, with the emphasis that there was no penalty if they did not participate. Two hundred (200) participants consented to participate in this survey with 189 (94\%) questionnaires returned; the participants included male and female patients aged between 19-70 years who had experienced anxiety during their admissions. 


\subsection{Patient's satisfaction questionnaires}

The initial questionnaire was developed by this health care service based on literature review, in-depth interviews of hospital staff and focus groups of patients and nursing staff to determine the content validity and appropriateness of the questionnaire. These responses were reviewed and developed into a questionnaire format (10 Items) by an expert advisory group, validated and currently remains in use in this healthcare service for overall service satisfaction. Scoring was achieved with Likert-type pre-specified response alternatives on a five-point scale.

The researchers for this study added five Items to the 'Patients Satisfaction Questionnaire' as the study needed to reflect specific nursing intervention for anxiety in this health care setting. These additional 5 items were generated from the results of the nurses' interviews, and patients focus group specifically for this study, these items were 2, 3, 4, 5 and 14 (see Table 2) were submitted to a panel of experts in nursing practice, nursing education and psychometrics who rated each item for appropriateness as a behaviour related to patient satisfaction. New items included references to the effect of how the intervention helped with the symptoms e.g. Item 4. Combined with the current validity of the focus group, the face validity of the patient focus group addressed all the variants of patient satisfaction that are relevant to anxiety management.

Participants were asked to rate the extent to which they agreed with questionnaire statements: Strongly disagree $=1$, Disagree $=2$, Neutral $=3$, Agree $=4$, Strongly agree $=5$ (Likert-type responses), these statements were made explicit that the meaning were equal to Poor =1, Fair $=2$, Good $=3$, very good $=4$ and Excellent $=5$, and spaces were provided on each questionnaire items for participants to make additional comments about their experiences of their care. A problem is defined as an aspect of intervention that could, in the eyes of the patient, be improved upon.

\subsection{Procedure}

Ethics approval was granted by the principle researcher's university and the hospitals' health services. Patients were provided with a participant's information sheet, demographics survey with a question on willingness to recommend the hospital to others and a patients' satisfaction questionnaire to complete at discharge. Participant anonymity was assured and patients were asked to complete the questionnaire and return to a collection point in the hospital, sealed in the envelope provided.

\subsection{Data analyses}

Data were analysed using the Statistical Package for Social Sciences (SPSS), Version $18^{[22]}$. Descriptive statistics (frequencies, percentages, means and standard deviations) were used to analyse the demographic variables and participants ratings of the effectiveness of the nursing interventions in relieving patients' anxiety in the study hospitals mental health patients. Residuals were checked for normality to ensure that regression analysis could be performed on the data. Normality was checked by graphing the normal probability plot which did not detect any significant departure from normality. The regression analysis was undertaken to determine which items appeared to be significantly associated with patient satisfaction. To determine whether assessment of global satisfaction provides an optimistic picture of healthcare experiences and consequently underestimates the number of problems encountered. The differences in ratings between age groups, marital status, number of admissions and duration of hospitalisations also identified. All correlations reported are Spearman coefficients and the qualitative comments were analysed using content analysis.

\section{Results}

There were 189 patients who participated in this study, comprising of 88 (46.6\%) males and 101 (53.4\%) females. The Mean age of participants was 52.6 years ranged (20 to 70 years) with $31.2 \%$ between 31 to 40 years. The duration of hospitalisation in these mental health facilities varied from one week to four months, with $40.2 \%$ being in hospital for three weeks. The number of admissions ranged from one to more than six times with $49.2 \%$ of the participants being admitted for the first time. Table 1 displays the demographic characteristics of participants. 
Table 1. Demographic characteristics ( $\mathrm{n}=189)$

\begin{tabular}{|c|c|}
\hline Variables & Frequency (\%) \\
\hline \multicolumn{2}{|l|}{ Gender } \\
\hline Male & $88(46.6 \%)$ \\
\hline Female & $101(53.4 \%)$ \\
\hline \multicolumn{2}{|l|}{ Age } \\
\hline$<20$ & $8(4.2 \%)$ \\
\hline $21-30$ & $31(16.4 \%)$ \\
\hline $31-40$ & $59(31.2 \%)$ \\
\hline $41-50$ & $38(20.1 \%)$ \\
\hline $51-60$ & $26(13.8 \%)$ \\
\hline $61-70$ & $23(12.2 \%)$ \\
\hline$>70$ & $4(2.1 \%)$ \\
\hline \multicolumn{2}{|l|}{ Marital Status } \\
\hline Single & $71(37.6 \%)$ \\
\hline Married & $70(37.0 \%)$ \\
\hline Defacto & $12(6.3 \%)$ \\
\hline Widow & $8(4.2 \%)$ \\
\hline Separated & $12(6.3 \%)$ \\
\hline Divorced & $16(8.5 \%)$ \\
\hline \multicolumn{2}{|c|}{ Number of Admissions } \\
\hline $1^{\mathrm{st}}$ & $93(49.2 \%)$ \\
\hline $2^{\text {nd }}$ & $44(23.3)$ \\
\hline $3^{\text {rd }}$ & 35 (18.5\%) \\
\hline $4^{\text {th }}$ & $9(4.8 \%)$ \\
\hline $5^{\text {th }}$ & $1(0.5 \%)$ \\
\hline $6^{\text {th }}$ or more & $7(3.7 \%)$ \\
\hline \multicolumn{2}{|c|}{ Duration of Hospitalisation } \\
\hline 1 week & $16(8.5 \%)$ \\
\hline 2 weeks & $48(25.4 \%)$ \\
\hline 3 weeks & $76(40.2 \%)$ \\
\hline 1 month & $23(12.2 \%)$ \\
\hline 2 months & $20(10.6 \%)$ \\
\hline 3 months & $3(1.6 \%)$ \\
\hline 4 months & $3(1.6 \%)$ \\
\hline
\end{tabular}

Table 2 shows the Mean scores of the Patients questionnaire with over $90 \%$ of respondents indicating no problems, there were substantial and statistically significant differences $(p<0.001)$. Participants were asked to rate the effectiveness of the nursing interventions provided to them to relieve their anxiety while in hospital. The total Mean rating of all items were 3.70 (SD $=0.67$ ) for the responses. The total mean of five (5) items was 3.69 ( $\mathrm{SD}=0.66$ ) There were no significant differences in ratings between genders, age groups, marital status, number of admissions and duration of hospitalisations.

Table 3 shows correlation coefficients of the dimensions of patient anxiety intervention, age, and self-reported with patient reported satisfaction with nursing practice; age and self-reported health status are often cited as major determinants of satisfaction and, in this instance, were found to be significantly correlated. However, the levels of correlation were low. Modest but significant correlations were found between satisfaction and overall assessment of health status (Spearman rho=0.21, $p<0.001, \mathrm{n}=189$ ) and age (Spearman rho=0.10, $p<0.002, \mathrm{n}=179$ ). Higher correlations were found between dimensions of the survey and satisfaction. 
Table 2. Patients Satisfaction Questionnaire rating responses of the effectiveness of nursing interventions in relieving anxiety $(\mathrm{N}=189)$

\begin{tabular}{|c|c|c|}
\hline Variables & Mean & SD \\
\hline 1) I was able to manage my crisis more effectively. & 3.74 & 0.58 \\
\hline *The nurse helped me to manage my anxiety symptoms more effectively. & 3.72 & 0.61 \\
\hline *I have a better understanding of the role of medication in my anxiety treatment. & 3.67 & 0.62 \\
\hline *I was able to deal more effectively with my anxiety symptoms & 3.62 & 0.70 \\
\hline *I can change, recover and grow as a result of nursing interventions. & 3.78 & 0.62 \\
\hline I was encouraged to ask questions about my current condition and treatment. & 3.64 & 0.76 \\
\hline My questions about other treatment options and the role of medications were answered. & 3.64 & 0.70 \\
\hline $\begin{array}{l}\text { I was encouraged to attend various groups related to my treatment program. Nurses } \\
\text { respect my preference }\end{array}$ & 3.89 & 0.52 \\
\hline 9) I was given adequate information about my condition that I am currently experiencing. & 3.56 & 0.70 \\
\hline 10) I feel safe and comfortable while in hospital as nurses were sensitive to my needs. & 3.77 & 0.63 \\
\hline 11) My family were given opportunity to be involved in my care. & 3.68 & 0.81 \\
\hline 12) Nurses are always available when I needed them. & 3.64 & 0.70 \\
\hline 13) Nurses responded well to my needs, concerns and questions. & 3.79 & 0.54 \\
\hline 14) *I felt I was able to approach and talk to nursing staff when I felt anxious. & 3.69 & 0.79 \\
\hline 15) Nurses encouraged me to take part in planning my discharge. & 3.67 & 0.75 \\
\hline Total mean score of all items & 3.70 & 0.67 \\
\hline Total mean score of 5 items & 3.69 & 0.66 \\
\hline
\end{tabular}

Note. Statements: 5 = Strongly Agree, $4=$ Agree, 3 = Neutral, 2 = Disagree, 1 = Strongly Disagree

* 2, 3, 4, 5 and 14 (additional items)

Table 3. Spearman correlation of age, self- reported health status, and dimensions of the questionnaire with global evaluation of health care and likelihood of recommending hospital to family/friends (all correlations significant at $p<0.001)$

\begin{tabular}{llc}
\hline Item & Satisfaction & Willingness to recommend hospital \\
\hline Age & -0.11 & -0.17 \\
Self-reported health status & -0.17 & -0.11 \\
Information and education & -0.45 & -0.40 \\
Anxiety intervention & -0.35 & -0.32 \\
Environmental comfort & -0.43 & -0.39 \\
Emotional support & -0.56 & -0.50 \\
Respect for patient preferences & -0.53 & -0.47 \\
Involvement of family/friends & -0.39 & -0.46 \\
Continuity of care at discharge & -0.39 & -0.34 \\
\hline
\end{tabular}

Note. Because of differences in direction in the coding of variables, a negative correlation indicates a positive relationship.

Table 4 indicates the level of satisfaction reported by participants of their nursing intervention. Most participants described their experience as good, very good, or excellent. This finding is consistent with the results from their comments in which $89.8 \%(n=189)$ of respondents indicated they would recommend the hospital to family and friends. Not surprisingly, the results from the two items were highly correlated (rho=0.64, $p<0.001 ; \mathrm{n}=189$ ). 
Table 4. Patients' satisfaction with their nursing care over all $(\mathrm{N}=189)$ broken down by number of issues affirmed as being satisfactory on the questionnaire

\begin{tabular}{llllll}
\hline & Strongly disagree & Disagree & Neutral & Agree & Strongly agree \\
\hline $\mathrm{N}$ & 0 & 1 & 44 & 86 & 58 \\
Minimum & 0 & 9 & 3 & 0 & 0 \\
Maximum & 0 & 34 & 27 & 25 & 24 \\
Mean & 0 & 14.50 & 22.81 & 9091 & 5.44 \\
(SD) & 0 & 5.09 & 5.88 & 5.37 & 4.09 \\
\hline
\end{tabular}

Table 5. Results from a multivariate linear regression showing strength of association, indicated by standardised regression coefficients and unstandardized regression coefficients (and 95\% confidence intervals) between overall evaluation of care and age, self-reported health status, sex, and dimensions on the Patients satisfaction questionnaire

\begin{tabular}{lccc}
\hline & Standardized coefficients & $\begin{array}{l}\text { Unstandardized coefficients } \\
\text { (95\% CI) }\end{array}$ & $\boldsymbol{p}$ values \\
\hline Age (in years) & 0.05 & $0.002(0$ to 0.004$)$ & $<0.02$ \\
Sex & -0.01 & $-0.0185(-0.087$ to 0.050$)$ & 0.60 \\
Information and education & 0.01 & $0.000(-0.001$ to 0.002) & 0.69 \\
Anxiety intervention & -0.05 & $-0.002(-0.004$ to 0.002$)$ & $<0.01$ \\
Environmental comfort & -0.21 & $-0.001(-0.014$ to -0.10$)$ & $<0.01$ \\
Emotional support & -0.29 & $-0.009(-0.011$ to -0.007$)$ & $<0.01$ \\
Respect for patient & -0.21 & $-0.007(-0.009$ to -0.006$)$ & $<0.01$ \\
Involvement of family \& & -0.06 & $-0.002(-0.003$ to 0$)$ & $<0.01$ \\
friends & & & \\
Continuity of care & -0.08 & $0.002(-0.003$ to -0.001$)$ & \\
at discharge & & & \\
\hline
\end{tabular}

Note. Constant $=4.77$. Overall evaluation of care measured on a scale where $5=$ Strongly Agree, $4=$ Agree, $3=$ Neutral, $2=$ Disagree, $1=$ Strongly Disagree

Table 5 shows both standardized and unstandardized coefficients and levels of significance of self-reported in anxiety status, together with the questionnaire domains as independent variables and the 5-point satisfaction scale as the dependent variable in a linear regression. An adjusted R2 $=0.48$ was achieved. The results suggest that the major determinants of patient satisfaction with the anxiety intervention, emotional support, and respect for patient preferences $(p<0.00001)$, treatment option for care $(p<0.01)$, involvement of family and friends $(p<0.0001)$, and continuity of care at discharge $(p<0.001)$ also contributed to the results. Another potential source of satisfaction is the number of items on which participants report problems, so the total number of problems reported by each patient (range 0-40) was calculated. Patient overall satisfaction was highly correlated with the number of items completed (Spearman rho $=0.65, p<0.001, \mathrm{n}=189$ ). The association of level of satisfaction with number of items completed is evident from descriptive statistics.

The data from the patients' comments on the questionnaire were analysed using content analysis and sorted into meaningful categories and eventually into themes.

Table 6. Themes from patients' comments on questionnaire

\begin{tabular}{ll}
\hline $\mathbf{N}=\mathbf{1 8 9}$ & Frequency (\%) \\
\hline Themes & \\
Access to nurses & $65 \%$ \\
Nursing intervention for anxiety & $75 \%$ \\
Emotional support & $85 \%$ \\
Use of medication & $90 \%$ \\
Involvement with plan of care and discharge & $80 \%$ \\
Understand their anxiety symptoms & $95 \%$ \\
\hline
\end{tabular}




\subsection{Access to nurses}

In terms of access, $65 \%$ of participants agreed or strongly agreed with the statement that it was easy to access nurses when they first had difficulties. On the anxiety issue and initial contact, $90 \%$ of patients agreed or strongly agreed that their initial contact with the nursing staff was very useful.

\subsection{Nursing intervention for anxiety}

Three-quarters (75\%) of participants agreed or strongly agreed that the nurses supported them with interventions such as relaxation sessions. The majority (78\%) of participants agreed or strongly agreed that they were offered support with education strategies to deal with their anxiety.

\subsection{Psychological and emotional support}

Eighty-five (85\%) agreed or strongly agreed that they were offered help to cope with troubling thoughts and feelings, while $15 \%$ were ambivalent and scored 'neither agree nor disagree'. Nearly two-thirds (63\%) of participants agreed or strongly agreed that they had received sustained engagement from the nursing staff even when they did not want to engage, while $30 \%$ reported that this was not applicable to them and $7 \%$ failed to respond.

\subsection{Use of medication}

Nearly all (90\%) of participants agreed or strongly agreed that they could discuss medication and $80 \%$ agreed or strongly agreed they had opportunities to discuss side-effects and 13\% agreed that medication was not their first option. They tried using nursing strategies e.g. deep breathing exercises.

\subsection{I nvolvement and plan of care for discharge}

Eighty percents (80\%) of participants agreed or strongly agreed that they felt actively involved with their care plan, while $10 \%$ disagreed.

\subsection{Understanding their anxiety symptoms}

The vast majority (85\%) of participants agreed or strongly agreed that nurses had helped them to understand their problems and had helped them to cope with difficulties in controlling their anxiety, $11 \%$ neither agreed nor disagreed and $4 \%$ disagreed. Nearly all (90\%) of participants agreed or strongly agreed that they knew whom to contact at any time for help.

\section{Discussion}

These results are in agreement with previous research on patient satisfaction, but go further in that they indicate that more meaningful information is gained when patients are asked to report on specific aspects of their experience of care. It has been suggested that age and health status are major influences on patient satisfaction ${ }^{[10]}$. However, the most important determinants, as indicated by the regression, appear to be anxiety intervention, emotional support and respect for patient.

In determining current nursing practice meeting the needs of patients experiencing anxiety, the majority of participants responded positively to most items on the questionnaires, indicating that, on the whole, the nursing team's interventions were very effective. Participants reported that they needed support during significant levels of stress and that nursing staff had provided positive and useful strategies that significantly reduced their stress levels, and therefore reduced their anxiety. These findings are particularly encouraging and concur with the study of Kuipers and Raune ${ }^{[23]}$ that positive support and strategies had helped patients to cope with their anxiety. 
The results highlighted the contribution of nurses in assisting patients in coping with difficulties associate with anxiety and for patients to begin to understand their illness symptoms and prevent further deterioration.

Giving patients a sense of optimism and control in the future management of their anxiety is a significant part of support. Empowering patients with mental health illness and specifically anxiety is central to their own coping. The importance in nurturing a sense of empowerment ${ }^{[24-26]}$ is the mental health nurses' role to provide encouragement and support, to develop connections with patients and family.

The evidence presented here would suggest that patient satisfaction scores and the related issues of willingness to recommend these hospitals to others presents an optimistic picture. The study has highlighted specific aspects of patients' experiences that could be used to evaluate other areas of care.

\section{Limitations}

It is necessary to interpret the largely positive findings of the study with some caution. It has been suggested that results may reflect either a general attitude of criticism towards the service or some loyalty rather than a measure of satisfaction itself ${ }^{[27-30]}$. The methodological limitations in this study are those found in any such study; unsatisfied patients may be those who chose not to respond to the survey. Views therefore may only reflect those who responded to the survey. The five-point Likert scale was open to bias of a set response type, to either consistently over-score or under-score responses.

We attempted to improve content validity and tried to ensure face validity by using the pre validated scale.

\section{I mplications for practice}

The results of the study demonstrated the importance of improving patient's awareness of anxiety and how to access help when it occurred. The positive mental health nursing contribution should include teaching more productive coping techniques and relapse prevention. Working closely with patients and promoting hope for relatives is another area that services should focus on as it has been shown that involving patients and relatives is critical when planning appropriate and acceptable care for them.

\section{Conclusion}

These results are in agreement with previous research on patient satisfaction, but go further in that they indicate that more meaningful information is gained when patients are asked to report on specific aspects of their experience of care.

This study provides a perspective on practice guidelines for nursing intervention for patients' experiencing anxiety. However, working with a person with anxiety requires in-depth theoretical and personal knowledge that is acquired only with time, understanding, and experience. The evidence of this study would suggest that it can provide meaningful information in the development of a nursing model of intervention and management for people with anxiety, which in turn can be used to improve service delivery in specific areas.

\section{Acknowledgements}

The authors would like to thank the participants for their time and effort in completing the questionnaire. This study was sponsored by a research grant from the St John of God Health Care. 


\section{References}

[1] TQA Research. Victorian Patient Satisfaction Monitor, Annual Survey Report, Year Three [Internet]. 2004. Available from: http://www.health.vic.gov.au/patsat/

[2] Andrews G, Davis M, Titov N. Effectiveness randomized controlled trial of face to face versus Internet cognitive behaviour therapy for social phobia. Australian and New Zealand Journal of Psychiatry. 2011; 45(4): 337-340. PMid:21323490 http://dx.doi.org/10.3109/00048674.2010.538840

[3] Andrews, G., Henderson, S. Unmet need in psychiatry. Problems, resources, responses. Cambridge. 2000. Cambridge University Press. http://dx.doi.org/10.1017/CBO9780511543562

[4] Gavin A, Hobbs, MJ. Borkovec, T. Beesdo, K. et al. Generalized worry disorder: A review of DSM -IV Generalized Anxiety Disorder and Options for DSM-V. Depression and Anxiety. 2010; 0: 1-14.

[5] Jorm, A. Christensen, H, Griffiths, K. Parslow, R. Rodgers, B., Blewitt, K. Effectiveness of complementary and self-help treatments for anxiety disorders. MJA. 2004; 18: S29-S46.

[6] Harkness, E. F. P. J. Bower. "On-site mental health workers delivering psychological therapy and psychosocial interventions to patients in primary care: effects on the professional practice of primary care providers." Cochrane Database of Systematic Reviews. 2009.

[7] Montgomery, C., Melchor-Beaupré, R. Stress and Social Problem Solving: Another Wonderful Symbiosis. Journal of Cognitive Education and Psychology. 2004; 4 (1): 87-111. http://dx.doi.org/10.1891/194589504787382811

[8] Brookes, N. "Phil Barker: Tidal Model of Mental Health Recovery" Ch 32 in AM Tomey and MR Alligood (Eds) Nursing Theorists and Their Work (6th Edition) St Louis, MI: Mosby Elsevier. 2006.

[9] Nuika, M., Paunonen, M., Hanninen, O., et al. The nurse’s workload in care situations. Journal of Advanced Nursing. 2000; 33:406-415. PMid:11251728 http://dx.doi.org/10.1046/j.1365-2648.2001.01676.x

[10] Cooper, L. A., Brown, C., Vu, H. T., Palenchar, D. R., Gonzales, J. J., Ford, D. E., et al. (2000). Primary care patients' opinions regarding the importance of various aspects of care for depression. General Hospital Psychiatry. 2000; 22:163-173. http://dx.doi.org/10.1016/S0163-8343(00)00073-6

[11] Fawcett, J. Analysis and evaluation of conceptual models of nursing (3rd ed.). Philadelphia: Davis. 1995.

[12] Jenkinson, C; Coulter, A, Bruster, S, Richards, N. Chandola, T. Patients' experiences and satisfaction with health care: results of a questionnaire study of specific aspects of care. Qual Saf Health Care .2002; 11:335-339. PMid:12468693 http://dx.doi.org/10.1136/qhc.11.4.335

[13] Hunot, V., Churchill, R., Teixeira. V., Silva de Lima, M. Psychological therapies for generalised anxiety disorder. The Cochrane Database of Systemic Reviews. 2007.

[14] Bushnell, J., Gellatly, R., Oakley-Browne, M. et al. Guidelines for assessing and treating anxiety disorders. Wellington: National Health Committee. 1998.

[15] Bebbington P, Brewin CR, Marsden L, Lesage A. Measuring the need for psychiatric treatment in the general population: the community version of the MRC Needs for Care Assessment. Psychol Med. 1996; 26(2):229-236. http://dx.doi.org/10.1017/S0033291700034620

[16] Heideman, J., van Rijswijk, E., van Lin, N. et al. 2005. Interventions to improve management of anxiety disorders in general practice: a systematic review. Br J Gen Pract. 2005; 55(1): 867-873. PMid:16282004

[17] Barker, P. The Tidal Model: developing an empowering, person-centred approach to recovery within psychiatric and mental health nursing. Journal of Psychiatric \& Mental Health Nursing. 2001; 8(3): 233-240. PMid:11882132 http://dx.doi.org/10.1046/j.1365-2850.2001.00391.x

[18] Shanley, E; Jubb-Shanley, M. The recovery alliance theory of mental health nursing. Journal of Psychiatric and Mental Health Nursing. 2007; 14(8):734-743. PMid:18039296 http://dx.doi.org/10.1111/j.1365-2850.2007.01179.x

[19] Dearing, E. Getting it, together: how the nurse patient relationship influences treatment compliance for patients with schizophrenia. Arch Psychiatr Nurs. 2004; 18(5):155-63. PMid:15529280 http://dx.doi.org/10.1016/j.apnu.2004.07.002

[20] Patton, D. Reality orientation: its use and effectiveness within older person mental health care. J Clin Nurs 2006; 15(11):1440-9. PMid:17038105 http://dx.doi.org/10.1111/j.1365-2702.2005.01450.x

[21] Jones, A. The value of Peplau's theory for mental health nursing. Br J Nurs. 1996; 5(14):877-81. PMid:8718356

[22] Carver, R Jane Gradwohl Nash, J. Doing Data Analysis with SPSS, Version 18 2011, C2012; Boston, MA: Brooks/Cole Cengage Learning.

[23] Kuipers, E., Raune, D. The early development of EE and burden in the families of first onset psychosis. In Early Intervention in Psychosis. A Guide to Concepts, Evidence and interventions (eds M Birchwood \& D Fowler) Chichester: John Wiley \& Sons, 2000; $128-140$. 
[24] Jacobson, N., Greenley, D. A Conceptual Model of Recovery. Psychiatric Services. 2001; 52 (5): 688-689. PMid:11331811 http://dx.doi.org/10.1176/appi.ps.52.5.688

[25] Morley, B., Pirkis, J., et al. "Better outcomes in mental health care: impact of different models of psychological service provision on patient outcomes." Australian \& New Zealand Journal of Psychiatry. 2007; 41(2): 142-9. PMid:17464692 http://dx.doi.org/10.1080/00048670601109915

[26] Brown, R. Describing a model of nursing as a focus for psychiatric nursing care. Int J Psychiatr Nurs Res. 2000 ; 6(1): 670-82. PMid:11261021

[27] O’Toole, M. S., Ohlsen, R. I., Taylor, T. M., Purvis, R., Walters, J., Pilowsky, L. S. Treating first episode psychosis- The service-users' perspective: A focus group evaluation. Journal of Psychiatric and Mental Health Nursing. 2004; 11: 319-326. PMid:15149380 http://dx.doi.org/10.1111/j.1365-2850.2004.00730.x

[28] Staniszewska, S., Ahmed, L. The concepts of expectation and satisfaction: Do they capture the way patients evaluate their care? Journal of Advanced Nursing.1999; 29: 364-372. PMid:10197936 http://dx.doi.org/10.1046/j.1365-2648.1999.00897.x

[29] Sitzia, J. How valid and reliable are patient satisfaction data? An analysis of 195 studies. International Journal for Quality in Health Care. 1999; 11 (4): 319-328. PMid:10501602 http://dx.doi.org/10.1093/intqhc/11.4.319

[30] Gray, R. et al. A survey of patient satisfaction with and subjective experiences of treatment with antipsychotic medication. Journal of Advanced Nursing. 2005; 52: 31-37. PMid:16149978 http://dx.doi.org/10.1111/j.1365-2648.2005.03561.x 